ACCEPTED MANUSCRIPT

\title{
Pulsed cavitational therapy using high-frequency ultrasound for the treatment of deep vein thrombosis in an in vitro model of human blood clot
}

To cite this article before publication: Guillaume Goudot et al 2017 Phys. Med. Biol. in press https://doi.org/10.1088/1361-6560/aa9506

\section{Manuscript version: Accepted Manuscript}

Accepted Manuscript is "the version of the article accepted for publication including all changes made as a result of the peer review process, and which may also include the addition to the article by IOP Publishing of a header, an article ID, a cover sheet and/or an 'Accepted

Manuscript' watermark, but excluding any other editing, typesetting or other changes made by IOP Publishing and/or its licensors"

This Accepted Manuscript is (C) 2017 Institute of Physics and Engineering in Medicine.

During the embargo period (the 12 month period from the publication of the Version of Record of this article), the Accepted Manuscript is fully protected by copyright and cannot be reused or reposted elsewhere.

As the Version of Record of this article is going to be / has been published on a subscription basis, this Accepted Manuscript is available for reuse under a CC BY-NC-ND 3.0 licence after the 12 month embargo period.

After the embargo period, everyone is permitted to use copy and redistribute this article for non-commercial purposes only, provided that they adhere to all the terms of the licence https://creativecommons.org/licences/by-nc-nd/3.0

Although reasonable endeavours have been taken to obtain all necessary permissions from third parties to include their copyrighted content within this article, their full citation and copyright line may not be present in this Accepted Manuscript version. Before using any content from this article, please refer to the Version of Record on IOPscience once published for full citation and copyright details, as permissions will likely be required. All third party content is fully copyright protected, unless specifically stated otherwise in the figure caption in the Version of Record.

View the article online for updates and enhancements. 


\section{Pulsed cavitational therapy using high-frequency}

2 ultrasound for the treatment of deep vein thrombosis in
4
G. Goudot ${ }^{1}$, T. Mirault ${ }^{2,3}$,
B. Arnal ${ }^{1}$,
C. Boisson-Vidal ${ }^{4}$,
B. Le Bonniec ${ }^{4}, P$.

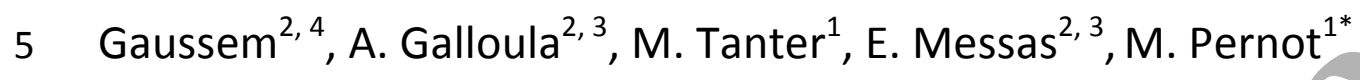

(1) Institut Langevin, INSERM U979, ESPCI Paris, CNRS UMR 7587, PSL Research

7 University, Paris, France

(2) Georges-Pompidou European Hospital, APHP, Paris Descartes University - USPC

9 Sorbonne Paris Cité, Paris, France

(3) INSERM U970 PARCC, Paris Descartes University - USPC Sorbonne Paris Cité University, Paris, France

(4) INSERM UMRS 1140, Paris Descartes University - USPC Sorbonne Paris Cité University,

$14 \quad *$ : Corresponding author

MP and EM share the senior co-authorship

\section{Abstract}

To reproduce venous thrombosis conditions, human whole blood was allowed to clot by stasis in silicone tubes (6 mm internal diameter) at a $30 \mathrm{cmH}_{2} \mathrm{O}$ pressure, maintained during 
1 transducers centered around a $6 \mathrm{MHz}$ imaging probe. A therapeutic focus was generated at 2 a $3.2 \mathrm{~cm}$ depth from the probe. Thrombotripsy was performed by longitudinally scanning the 3 thrombus at 3 different speeds: $1 \mathrm{~mm} \cdot \mathrm{s}^{-1}(\mathrm{n}=6) ; 2 \mathrm{~mm} \cdot \mathrm{s}^{-1}(\mathrm{n}=6) ; 3 \mathrm{~mm} \cdot \mathrm{s}^{-1}(\mathrm{n}=12)$. Restored 4 outflow was measured every 3 passages. Filters were placed to evaluate the debris size.

524 occlusive thrombi, of $2.5 \mathrm{~cm}$ mean length and $4.4 \mathrm{kPa}$ mean stiffness, were studied. 6 Flow restoration was systematically obtained by 9 subsequent passages ( 4.5 min maximum). 7 By varying the device's speed, we found an optimal speed of $1 \mathrm{~mm} \cdot \mathrm{s}^{-1}$ to be efficient for 8 effective recanalization with $90 \mathrm{~s}$ (3 passages). Within $90 \mathrm{~s}$, flow restoration was of 80, 62 9 and $74 \%$ at respectively 1,2 and $3 \mathrm{~mm} \cdot \mathrm{s}^{-1}$. For all groups, cavitation cloud drilled a $1.7 \mathrm{~mm}$ 10 mean diameter channel throughout the clot. Debris analysis showed $92 \%$ of debris $<10 \mu \mathrm{m}$, 11 with no fragment $>200 \mu \mathrm{m}$.

12

13 CONCLUSION: High-frequency thrombotripsy allowed fast and effective recanalization of 14 whole-blood thrombus in vitro, without any parietal alteration or bulky debris formation.

Keywords: thrombolysis - histotripsy - venous thrombosis - therapeutic ultrasound 17 Word count: abstract: 252 words, manuscript 2860 words. 


\section{Purpose}

2 Deep venous thrombosis of the lower limbs is a frequent disease, affecting approximately $30.1 \%$ to $0.2 \%$ of people per year $[1,2,3]$. The main initial risk is the migration of 4 fibrinocruoric emboli responsible for pulmonary embolism in about $30 \%$ of cases (Heit et al 2016). In the long term, the main risk for proximal thrombosis is the appearance of postthrombotic syndrome in about 20 to 50 \% of cases (Kahn et al 2015), with an increased incidence in cases of iliofemoral persistent occlusion (Delis et al 2004). It is characterized by functional impotence, pain, pruritus and distal trophic disorders, with a major alteration of the quality of life (Kahn et al 2008). Current treatment of venous thrombosis is based on effective anticoagulation, expected to avoid embolic migration and to reduce morbidity and mortality. On the other hand, anticoagulation is frequently inefficient for recanalizing the occluded vessel $[6,7]$, with a consequently low influence on the incidence of postthrombotic syndrome. Several studies suggest that the flow restoration in the occluded vein allows for long-term venous recanalization and thus limits the risk of post-thrombotic syndrome (Watson and Armon 2004, Enden et al 2012). The use of plasminogen activators or other thrombolytic agents has been shown to significantly improve the repermeabilization of the occluded vein. It was however associated with a $10 \%$ rate of severe haemorrhagic events (Watson and Armon 2004). Similarly, effective endovascular invasive recanalization procedures were associated with a decrease in post-thrombotic syndrome at 6 weeks (Enden et a/2012) whereas the persistence of a residual thrombus was associated with an increased risk of post-thrombotic syndrome (Comerota et al 2012). However this intervention is associated with a substantial risk of hematoma, false aneurysm, reocclusion or stent rupture.

Therapeutic ultrasound has been investigated by several groups as a promising drug-free approach for non-invasive recanalization in deep venous thrombosis settings. Various techniques such as histotripsy based on short high intensity ultrasound pulses or High Intensity Focused Ultrasound (HIFU) based on longer excitation pulses have been proposed as a way to fragment thrombi by acoustic cavitation without the need of injecting 29 microbubbles. Vascular wall damage can however be observed when cavitation occurs near 30 the vessel walls (Maxwell et al 2009). To overcome this issue, microtripsy has been recently 31 introduced to generate a cavitation cloud contained in a small volume, therefore avoiding 
1 any damage to the vessel walls (Zhang et al 2015b). Microtripsy requires a very high negative 2 pressure to reach the intrinsic cavitation threshold $(-30 \mathrm{MPa})$, which remains challenging to 3 achieve in vivo. We propose hereby an alternative approach by increasing the ultrasound 4 frequency (a frequency lower than $1.5 \mathrm{MHz}$ is used in most histotripsy applications) in order 5 to decrease the focus size and achieve very accurate fragmentation of the thrombus without 6 damaging the vessel walls. The goal of this study was to 1) evaluate the feasibility of this 7 approach on an in vitro model of human blood clot, 2) assess the recanalization efficacy of pulsed cavitational ultrasound and 3) quantify the size of the debris.

\section{Materials and methods}

1) Obtaining an occlusive thrombus

Human citrated (3.2\%) whole blood was obtained from healthy volunteers from the French Blood Bank Institute (Etablissement Français du Sang, Paris, France, agreement ref. C CPSL UNT $\left.n^{\circ} 13 / E F S / 064\right)$. The subjects had normal complete blood count, denied having taken drugs interfering with haemostasis in the past 10 days and gave written informed consent. Coagulation was induced by adding $20 \mathrm{mM}$ calcium chloride $(\mathrm{CaCl} 2$, number $\mathrm{C}$ 5080; Sigma Chemical ${ }^{\odot}$, St. Louis, MO, USA). Aprotinin (100 kJU/mL final concentration; Trasylol $500000 \mathrm{kIU} / 50 \mathrm{~mL}$, Bayer ${ }^{\odot}$ ) was added to block the endogenous fibrinolysis during the recanalization procedure. Clots of $2.5 \mathrm{~cm}$ in length were obtained by coagulation under stasis at $37{ }^{\circ} \mathrm{C}$ in sealed roughened silicone tubes $(6 \mathrm{~mm}$ wide, $1 \mathrm{~mm}$ thick, close to the characteristics of the human femoral vein) and held in vertical position for 1 hour after the deposition of $0.8 \mathrm{ml}$ of citrated whole blood. After coagulation and thrombus retraction, the cap was removed and the tube placed horizontally and charged with a saline solution $(0.9 \%$ $\mathrm{NaCl}$ ) via a pressure column at $30 \mathrm{~cm} \mathrm{H}_{2} \mathrm{O}$. Non-obstructive thrombi were not retained for the experiments. The silicon tube was positioned in order to approach a realistic depth based on an example of human femoral vein (Figure 1).

2) Thrombi stiffness evaluation

Shear wave elastography was performed using a clinical ultrafast scanner (Aixplorer ${ }^{\circledR}$, Supersonics Imagine ${ }^{\odot}$, Aix-en-Provence, France) and a linear ultrasound probe (SL10-2, central frequency $6 \mathrm{MHz}, 192$ elements). Thrombus stiffness was obtained by measuring the 
mean elasticity of three circular regions of interest at a distance from the walls to avoid interference with the silicone tube's wall stiffness.

3) Thrombotripsy device

Using an in-house heterodyne interferometer (Royer et al 1992), two $2.25 \mathrm{MHz}$ focused transducers (central frequency $2.25 \mathrm{MHz}$, focal distance $38 \mathrm{~mm}, \mathrm{~F} / \mathrm{D}=1$, Imasonic ${ }^{\circ}$, Voraysur-l'Ognon, France) were positioned confocally on either side of a SL10-2 probe. The whole system was assembled thanks to 3D printed parts, immersed in a degassed water-bath, and moved by a motor along the silicone tube. The focal point was located $3.2 \mathrm{~cm}$ away from the imaging probe (Figure 2). The size of the focal spot $(-6 \mathrm{~dB})$ in the plane of the 2 transducers was $0.45 \times 1.25 \mathrm{~mm}$ at low pressure. The transducers alone had a theoretical focal spot of $0.67 \mathrm{~mm} \times 4.667 \mathrm{~mm}$. Using these two aperture confocal transducers allowed reaching high enough peak negative pressure for cavitation inception even though their aperture was small (38 $\mathrm{mm}$ diameter). The use of two confocal transducers allowed reducing the nonlinear propagation effects as shown in simulation by Fowler et al. and Lafond et al. (Fowler et al 2013, Lafond et al 2017). As a consequence, such a setup allowed a better spatial localization of the focal point and a higher negative pressure compared to what would be generated by a single large aperture. The two transducers were driven by a signal generator (Tektronix@) amplified by a gain of $60 \mathrm{~dB}$ by a $2.5 \mathrm{~kW}$ power amplifier (GA-2500, RITEC@), USA). The signals were composed of bursts of 8-cycles at $2.25 \mathrm{MHz}$ transmitted with a Pulse Repetition Frequency (PRF) of $100 \mathrm{~Hz}$. The negative pressure's peak generated at the focus of the two confocal transducers was measured with an optical interferometer at -15 MPa.

\section{4) Recanalization:}

The SL10-2 probe was used to appropriately align the device with the tube in order to place the focal spot in the center of the tube. Each group received 3 sequences of cavitation ( 1 sequence $=3$ passages) along the thrombus, with assessment of the restored flow after each sequence. One passage is the displacement of the device along the thrombus length. We fixed three different passage speeds along the thrombus: $1 \mathrm{~mm} . \mathrm{s}^{-1}(\mathrm{n}=6 ; 1$ passage $=30$ s), $2 \mathrm{~mm} \cdot \mathrm{s}^{-1}(\mathrm{n}=6: 1$ passage $=15 \mathrm{~s})$ and $3 \mathrm{~mm} \cdot \mathrm{s}^{-1}(\mathrm{n}=12 ; 1$ passage $=10 \mathrm{~s})$. Thus, the total cavitation time ( 3 sequences) ranged between $1.5 \mathrm{~min}\left(\right.$ at $3 \mathrm{~mm} \cdot \mathrm{s}^{-1}$ ) to $4.5 \mathrm{~min}$ (at $1 \mathrm{~mm} \cdot \mathrm{s}^{-1}$ ). The drilled channel was longitudinally scanned by plane-by-plane volumetric acquisition with 
1 a dedicated probe (SuperLinear ${ }^{\mathrm{TM}}$ Volumetric SLV16-5, Supersonics, Aix en Provence, France)

2 to assess the continuity of the thrombus recanalization.

5) Outflow evaluation

After each sequence, outflow was investigated by measuring the volume of the outflow solution for a defined period of 1 minute. Initial flow measurement was carried out after mounting the tube with the pressure column $\left(30 \mathrm{cmH}_{2} \mathrm{O}\right.$ i.e. $22 \mathrm{mmHg}$ ). Results are expressed as a percentage of the maximum flow rate (flow rate measured with the silicone tube without thrombus under the same conditions).

6) Debris analysis

The outflow was filtered through 2 consecutive filters with $100 \mu \mathrm{m}$ and $40 \mu \mathrm{m}$ nylon mesh filters (Cell Stainer, BD Biosciences ${ }^{\odot}$ ). Each filter was rinsed with a saline solution, dried, and analysed under an optical microscope. Debris were counted by scanning the whole filter under a microscope, using x100 and x200 optical magnifications. Small debris $(<40 \mu \mathrm{m})$ were collected and then analysed by sampling using a computerised counter (Cell Counter BioRad Laboratory $\left.{ }^{\circledR}\right)$. The diameter distribution of the small debris is represented by the number of debris normalized to the removed thrombus volume.

7) Statistical analysis

Continuous variables, presented as their mean \pm standard deviation, were compared with the Mann-Whitney U-test, or Kruskal-Wallis test when comparing more than 2 groups (3 different speed groups). Variances between groups were compared using Levene's test with a Bonferroni correction for multiple comparisons. Two-sided $p$ values $<0.05$ were considered significant. All statistical computations used the R software.

\section{Results}

Twenty-four consecutive adherent thrombi were evaluated. After 1 hour of clot formation and retraction, the thrombus occupied the tube volume ( $6 \mathrm{~mm}$ internal diameter) and $2.51 \mathrm{~cm}$ in length on average. Only occlusive thrombi were retained, with a microflow through the thrombus lower than $0.5 \mathrm{~mL} \cdot \mathrm{min}^{-1}$. Shear wave elastography of the thrombus showed an average stiffness of $4.4 \pm 1.8 \mathrm{kPa}$, corresponding to a recent deep venous thrombosis (Mfoumou et al 2014). 
1 1) Recanalization efficiency:

$2 \quad$ Histotripsy formed a circular channel of $1.7 \pm 0.4 \mathrm{~mm}$ mean cross sectional diameter 3 throughout the clot (the average volume of thrombus removed was $5.70 \mathrm{~mm}^{3}$ ) (a movie of 4 the recanalization procedure is presented in the supplementary materials). Transverse 5 alignment of the device made it possible to center the cavitation cloud so it did not reach 6 the tube's walls. End experiment examination revealed a residual thrombus coating the 7 tube's inner walls of $2.1 \mathrm{~mm}$ mean thickness. This ensured that the cavitation cloud was well 8 centered and far from the tube's walls, while respecting the material's integrity (Figure 3).

9

2) Speed and time for thrombus recanalization

A speed of $1 \mathrm{~mm} \cdot \mathrm{s}^{-1}$ allowed efficient recanalization (80 $17 \%$ ) after only one sequence (3 passages), corresponding to a treatment duration of $90 \mathrm{~s}$ (Figure 4). For the same duration time, we obtained only $61 \pm 32 \%$ at $2 \mathrm{~mm} \cdot \mathrm{s}^{-1}$ and $74 \pm 22 \%$ at $3 \mathrm{~mm} \cdot \mathrm{s}^{-1}$ ( $\mathrm{p}=\mathrm{NS}$ for all groups). When comparing the time required for effective recanalization, regardless of the transducer's speed, an average time of $76 \pm 17 \mathrm{~s}$ was required to obtain a flow recovery at $70 \%$ and $101 \pm 45$ s for a flow at $80 \%$ of the initial flow (Figure 5). However, flow restoration variance between thrombi recanalizations was significantly lower at a speed of $1 \mathrm{~mm} \cdot \mathrm{s}^{-1}$, $7.4 \%$, compared to other speeds ( $32.5 \%$ for $2 \mathrm{~mm} . \mathrm{s}^{-1}: \mathrm{p}=0.003 ; 22.4 \%$ for $3 \mathrm{~mm} \cdot \mathrm{s}^{-1}: \mathrm{p}=0.027$ ).

3) Debris analysis

Gross examination of the $100 \mu \mathrm{m}$ filter at the end of each experiment revealed no macroscopic debris, whatever the speed group. Microscopic analysis of the nylon mesh filters (Figure 6) found rare debris (1.6 \pm 1.7 per thrombus) but none bigger than $200 \mu \mathrm{m}$, which is consistent with the gross examination findings (Figure 7). The small debris diameter distribution (less than $40 \mu \mathrm{m}$ ) is represented in Figure 8, according to the device's speed and reported by the number of debris, normalized to the removed thrombus volume. No significant difference was noticed between the three groups of speed: $p=0.30$ with the Kruskal-Wallis test. For the absolute number of small debris, a non-significant trend to an increase of small debris was observed at a speed of $1 \mathrm{~mm} \cdot \mathrm{s}^{-1}$, which corresponds to a slightly larger volume of recanalized channel $\left(89 \pm 29 \mathrm{~mm}^{3}\right.$ for $1 \mathrm{~mm} \cdot \mathrm{s}^{-1}$ vs. $50 \pm 14 \mathrm{~mm}^{3}$ for other speeds, $p=0.008)$ with a lower residual thrombus $(1.93 \pm 0.20$ vs. $2.20 \pm 0.11 \mathrm{~mm}, p=0.01)$. 


\section{Discussion}

We aimed at demonstrating the effectiveness of thrombotripsy to recanalize a silicon tube containing an occlusive thrombus obtained with human whole blood stasis, reproducing as closely as possible the conditions of a recent femoral vein thrombosis. For this reason, we performed thrombus in stasis at $37^{\circ} \mathrm{C}$, in whole blood obtained from fresh human blood. Obtaining a thrombus adhering well to the walls was an important step, in order to prevent the migration of the entire thrombus when loaded with the pressurized saline solution. Moreover, it avoided the use of stenosis to block the clot as used in other studies (Zhang et al 2015a, 2015b, 2016). We abandoned this procedure, first because it deviates from physiological conditions, second because when recanalization is performed, it turns out that the thrombus migrates inside the stenosis, therefore reducing the debris to be drained by the restored outflow. Our initial use of a $600 \mathrm{kHz}$ transducer failed to form a cavitation cloud within the channel without creating cavitation on the outer walls of the tube. This shielding reduced the acoustic power at the focus depth and thus the cavitation activity in the channel. Moreover, the formation of a large cavitation cloud could damage the vessel walls. Depending on the emitted acoustic power, the cavitation cloud position varied unpredictably.

In our study, the use of higher frequency confocal transducers solved these issues. It allowed forming a cloud of limited size with ișotropic dimensions $(2 \times 2 \times 2 \mathrm{~mm})$. Compared to large phased array systems powered with multi-channel electronics, this system was designed and built at a much lower cost. It induced a complete repeatability of the cavitation cloud position, which will enable a higher innocuousness of the treatment for future in vivo trials.

Sonothrombolysis usually corresponds to multiple techniques whose only common feature is the use of ultrasound during the thrombolysis procedure. The main techniques developed are High Intensity Focused Ultrasound (HIFU), for which the main advantage is the use of the thermal properties of ultrasound waves to facilitate the action of a chemical thrombolysis (Bader et al 2016, Wright et al 2012). Thrombus fragmentation techniques using microbubbles underlined the mechanical thrombolytic effects of gas microbubbles, which can be injected or directly formed by cavitation alone. In order to develop a strictly non-invasive technique, our work stands on a model of cavitation alone, according to 
1 previous work from the University of Michigan [11, 18, 19, 20]. In order to improve this 2 method, we used a higher frequency 2-channel device, developed a model close to the 3 human venous thrombosis and defined the optimal therapeutic time for a recent thrombus 4 length of $2.5 \mathrm{~cm}$ as studied herein. The advantage of our technique, even though it has not 5 been tested yet in vivo, is the use of a smaller device, easier to handle. Cavitation with our device can be achieved with commercially available generators and amplifiers.

Flow restoration was initiated as soon as a little channel was formed along the thrombus, with a rapid increase during the procedure related to the channel enlargement. Longitudinal alignment of the thrombus, with control of the channel drilling throughout the procedure, allowed rapid recanalization by performing continuous cavitation with a fixed transducer speed.

We defined the $1 \mathrm{~mm} \cdot \mathrm{s}^{-1}$ speed as the optimal speed of therapy from our 3 experimental conditions. Indeed, it allowed a minimal number of passages (3) to achieve the optimal flow rate $(>80 \%)$ with a short time of therapy $(90 \mathrm{~s})$. The time required to recanalize a thrombus did not depend significantly on the speed. At higher velocities ( 2 and $3 \mathrm{~mm} \cdot \mathrm{s}^{-1}$ ), complete recanalization required more passages, which ended to the same recanalization than at 1 $\mathrm{mm} \cdot \mathrm{s}^{-1}$. We can note, however, that a higher variability of the recanalization time was observed at higher speed. We can anticipate that a lower speed would also provide a complete recanalization, but it would require longer treatment time, which would increase the exposure risk of the vessel wall. Our objective being to allow a fast and safe recanalization, we did not choose to explore lower speeds than $1 \mathrm{~mm} . \mathrm{s}^{-1}$. This method of longitudinal thrombolysis greatly shortened the procedure's duration. However, this requires adapting the displacement of the transducer in order to follow the venous thrombus. Such a device can be developed using image guidance combined to a robotic arm.

The purpose of the thrombus recanalization procedure was not to remove the entire thrombus clotted inside the tube but to create a small flowing channel in the clot. Recanalization was conducted at a distance from the tube's walls, in order to limit as much as possible the risk of parietal injury. Moreover, even with a small diameter channel, good outflow (more than $80 \%$ of the maximal flow) was obtained. Although the presence of residual thrombus may expose to the risk of post-procedure venous occlusion, we plan in 31 further pre-clinical studies to perform the procedure under effective anticoagulation. We 
1 expect the recanalization to allow the heparin treatment to act locally and maintain the 2 vessel's permeability.

3 Thrombus elastography was achieved to verify our thrombosis model. An average 4 thrombus elasticity of $4.5 \mathrm{kPa}$ was consistent with the maturation time of 1 hour after in 5 vitro coagulation induction. According to the study carried out by Mfoumou et al [16], with 6 the same Aixplorer@ apparatus on in vivo thrombosis in the rabbit, $5 \mathrm{kPa}$ thrombus actually 7 corresponded to a thrombus triggered in 1 to 2 hours. We did not test our device on 8 thrombus with a higher stiffness, due to the conditions needed for thrombus maturation, 9 with a progressive enrichment in fibrin as well as the loss of the platelets, which could not be achieved in our in vitro conditions.

11 Debris formation is inherent to any recanalization procedure. The release of small debris 12 is necessary to allow secure venous recanalization. In our experiment, we did not notice any 13 macroscopic debris or any debris with a diameter over $200 \mu \mathrm{m}$. Occlusion of the pulmonary 14 artery or its proximal branches, responsible for proximal pulmonary embolism is only 15 triggered by bulky macroscopic thrombi. However, overall innocuousness of the debris 16 obtained is difficult to assess in vitro. During a perfusion lung scintigraphy, between 200000 17 and 700000 particles of albumin aggregates are injected, with a diameter between 10 and $1890 \mu \mathrm{m}$ and with a maximum diameter of $150 \mu \mathrm{m}$. Even though albumin aggregates will block 19 some lung capillaries (between $1 / 200$ and 1/1000 (Dworkin et al 1966)), this examination is 20 considered as safe, without significant hypoxemia due to arteriolar blockade (Renowden et 21 al 1991) and is performed in daily practice to diagnose pulmonary embolism. We mainly 22 obtained debris corresponding to fragments of red blood cells, size $<10 \mu \mathrm{m}$ not threatening 23 to the pulmonary vascular tree. Debris likely to obstruct a pulmonary arteriole, i.e. over 100 $24 \mu \mathrm{m}$ diameter in theory, were very scarce (more than $99 \%$ of the debris were under $40 \mu \mathrm{m}$ ). 25 The risk of poor tolerance due to the embolization of these debris is therefore very low with 26 a small number of affected arterioles.

27 The limitation of this in vitro model of deep venous thrombosis is the relatively short size 28 of the thrombus. This limits the procedure to suspended proximal thrombosis. Finally, the 29 potential danger of the debris requires a specific evaluation in animals. In order to obtain a 30 sufficient venous diameter close to the human femoral vein, the pig model is the smallest 31 animal model appropriate for this purpose, as already tested (Maxwell et al 2009, Zhang et 
1 al 2017). In an in vivo application, we need to consider tissue attenuation. With an average

2 depth of $3 \mathrm{~cm}$ of the femoral vein in pig, and an average tissue attenuation of $0.6 \mathrm{~dB} \cdot \mathrm{MHz}^{-}$

$3{ }^{1} . \mathrm{cm}^{-1}$, we expect a total attenuation of $4.05 \mathrm{~dB}$ with a $2.25 \mathrm{MHz}$ transducer. This 4 attenuation factor can be easily compensated by increasing the amplification gain by 1.6 5 fold. On the other hand with histotripsy, tissue heating remains limited due to the low

Acknowledgements:

We would like to thank Cardiawave ${ }^{\odot}$ for the funding support. We also thank Mrs. Beatrice Walker for her careful proofreading of the manuscript.

\section{References}

Bader K B, Bouchoux G and Holland C K/2016 Sonothrombolysis. Adv. Exp. Med. Biol. 880 339-62 Online: http://www.ncbi.n/m.nih.gov/pubmed/26486347

Comerota A J, Grewal N, Martinez J T, Chen J T, Disalle R, Andrews L, Sepanski D and Assi Z 2012 Postthrombotic morbidity correlates with residual thrombus following catheterdirected thrombolysis for iliofemoral deep vein thrombosis J. Vasc. Surg. 55 768-73 Online: http://dx.doi.org/10.1016/j.jvs.2011.10.032

Delis K T, Bountouroglou D and Mansfield A O 2004 Venous claudication in iliofemoral thrombosis: long-term effects on venous hemodynamics, clinical status, and quality of life. Ann. 239 118-26 Online: http://content.wkhealth.com/linkback/openurl?sid=WKPTLP:landingpage\&an=0000065 $29 \quad 8-200401000-00017$ 
1 Dworkin H J, Smith J R and Bull F E 1966 A reaction following administration of macroaggregated albumin (maa) for a lung scan. Am. J. Roentgenol. Radium Ther. Nucl.

列
Med. 98 427-33 Online: http://www.ncbi.nlm.nih.gov/pubmed/5925113

Enden T, Haig Y, Kløw N-E, Slagsvold C-E, Sandvik L, Ghanima W, Hafsahl G, Holme P A, Holmen L O, Njaastad A M, Sandbæk G and Sandset P M 2012 Long-term outcome after additional catheter-directed thrombolysis versus standard treatment for acute iliofemoral deep vein thrombosis (the CaVenT study): a randomised controlled trial. Lancet (London, England)

379 $31-8$ Online: http://www.ncbi.nlm.nih.gov/pubmed/22172244

Fowler R-A, Lafond M, Poizat A, Mestas J-L, Chavrier F, Béra J-C and Lafon C 2013 Inertial cavitation enhancement using confocal ultrasound J. Acoust. Soc. Am. 1344234

Heit J A, Spencer F A and White R H 2016 The epidemiology of venous thromboembolism J. Thromb. Thrombolysis 41 3-14 Online: http://www.ncbi.nIm.nih.gov/pubmed/26780736

Kahn S R, Comerota A J, Cushman M, Evans N S, Ginsberg J S, Goldenberg N A, Gupta D K and Prandoni P 2015 The Postthrombotic Syndrome: Evidence-Based Prevention, Diagnosis , and Treatment Strategies Circulation 130 1636-61

Kahn S R, Shbaklo H, Lamping D L, Holcroft C A, Shrier I, Miron M J, Roussin A, Desmarais S, Joyal F, Kassis J, Solymoss S, Desjardins L, Johri M and Ginsberg J S 2008 Determinants of health-related quality of life during the 2 years following deep vein thrombosis. J. Thromb. Haemost. 6 1105-12 Online: http://doi.wiley.com/10.1111/j.15387836.2008.03002.x

Lafond M, Prieur F, Chavrier F, Mestas J-L and Lafon C 2017 Numerical study of a confocal ultrasonic setup for cavitation creation. J. Acoust. Soc. Am. 1411953 Online: http://aip.scitation.org/doi/10.1121/1.4978061

Maxwell A D, Cain C A, Duryea A P, Yuan L, Gurm H S and Xu Z 2009 Noninvasive thrombolysis using pulsed ultrasound cavitation therapy - histotripsy. Ultrasound Med. Biol.

http://www.pubmedcentral.nih.gov/articlerender.fcgi?artid=2796469\&tool=pmcentrez \&rendertype=abstract

31 Maxwell A D, Owens G, Gurm H S, Ives K, Myers D D and Xu Z 2011 Noninvasive treatment of 

deep venous thrombosis using pulsed ultrasound cavitation therapy (histotripsy) in a porcine model. J. Vasc. Interv. Radiol. 22 369-77 Online: http://www.pubmedcentral.nih.gov/articlerender.fcgi?artid=3053086\&tool=pmcentrez \&rendertype=abstract

Messas E, Wahl D and Pernod G 2016 [Management of deep-vein thrombosis: A 2015 $\begin{array}{lllll}\text { update]. } & \text { J. } & \text { Mal. } & \text { Vasc. } & 41\end{array}$ Online: http://www.ncbi.nlm.nih.gov/pubmed/26357937

Mfoumou E, Tripette J, Blostein M and Cloutier G 2014 Time-dependent hardening of blood clots quantitatively measured in vivo with shear-wave ultrasound imaging in a rabbit model of venous thrombosis Thromb. Res. 133 265-71 Online: http://dx.doi.org/10.1016/j.thromres.2013.11.001

Patel K, Fasanya A, Yadam S, Joshi A A, Singh A C and DuMont T 2017 Pathogenesis and Epidemiology of Venous Thromboembolic Disease Crit. Care Nurs. Q. 40 191-200 Online: http://www.ncbi.nlm.nih.gov/pubmed/28557890

Popuri R K and Vedantham S 2011 The role of thrombolysis in the clinical management of deep vein thrombosis. Arterioscler. Thromb. Vasc. Biol. 31 479-84 Online: http://atvb.ahajournals.org/cgi/doi/10.1161/ATVBAHA.110.213413

Puurunen M K, Gona P N, Larson M G, Murabito J M, Magnani J W and O’Donnell C J 2016 Epidemiology of venous thromboembolism in the Framingham Heart Study Thromb. Res. 145 27-33 Online: http://dx.doi.org/10.1016/j.thromres.2016.06.033

Renowden S A, Dunne J A and Hayward M W 1991 Changes in arterial oxygen saturation during isotope perfusion scans using human macroaggregates of albumin. Nucl. Med. Commun. 12 959-63 Online: http://www.ncbi.nlm.nih.gov/pubmed/1754156

Royer D, Dubois N and Fink M 1992 Optical probing of pulsed, focused ultrasonic fields using a heterodyne interferometer Appl. Phys. Lett. 61 153-155

Watson L I and Armon M P 2004 Thrombolysis for acute deep vein thrombosis. Cochrane database Syst. Rev. CD002783 Online: http://www.ncbi.nIm.nih.gov/pubmed/15495034

Wright C, Hynynen K and Goertz D 2012 In vitro and in vivo high intensity focused ultrasound thrombolysis Invest. Radiol. 47217

Zhang X, Macoskey J J, Ives K, Owens G E, Gurm H S, Shi J, Pizzuto M, Cain C A and Xu Z 2017 
1 Non-invasive Thrombolysis Using Microtripsy in a Porcine Deep Vein Thrombosis Model 2 Ultrasound

Med.

Biol.

Online:

3 http://www.sciencedirect.com/science/article/pii/S0301562917300595

4

Zhang X, Miller R M, Lin K-W, Levin A M, Owens G E, Gurm H S, Cain C A and Xu Z 2015a Real-

5 time feedback of histotripsy thrombolysis using bubble-induced color Doppler.

6 Ultrasound Med.

Biol.

41 1386-401

Online:

7 http://www.umbjournal.org/article/S030156291400800X/fulltext

8

Zhang X, Owens G E, Cain C A, Gurm H S, Macoskey J and Xu Z 2016 Histotripsy Thrombolysis 9 on Retracted Clots. Ultrasound Med. Biol. 42 1903-18 Online: http://linkinghub.elsevier.com/retrieve/pii/S0301562916300035

Zhang X, Owens G E, Gurm H S, Ding Y, Cain C A, Arbor A, Diseases C, Arbor A and Arbor A 12 13 2015b Non-invasive Thrombolysis using Histotripsy beyond the 'Intrinsic' Threshold (Microtripsy) IEEE Trans Ultrason Ferroelectr Freq Control 62 
$1 \quad$ VI. Figures Legends

2 Fig. 1. Comparison of the depth and diameter of the femoral vein in a patient with an

3 occlusive thrombus (A) versus the parameters used in our setup (B).

4

6 standardized to the removed thrombus volume. Debris count was obtained by the automatic

Fig. 2. Illustration of the thrombotripsy experimentation setup (A). The two transducers are coupled and centered by a linear probe of $7 \mathrm{MHz}(\mathrm{B})$. It is then immerged and centered on the occlusive thrombus in the silicon tube (C).

Fig. 3. Imaging of a recanalyzed thrombus. Ultrasonic acquisition before thrombolysis (A). Complete recanalization after 3 series of 3 passages of thrombotripsy (B). Volumetric acquisition with a dedicated probe confirms the recanalization's continuity, remotely from the walls (C).

Fig. 4. Rate of recanalization according to thrombotripsy passages and device's speed: 1 $\mathrm{mm} \cdot \mathrm{s}^{-1}$ (red), $2 \mathrm{~mm} \cdot \mathrm{s}^{-1}$ (purple), $3 \mathrm{~mm} \cdot \mathrm{s}^{-1}$ (blue). The restored outflow is presented as a percentage of the maximum flow (initial flow without thrombus).

Fig. 5. Recanalization rate according to the cavitation time. The restored outflow is presented as a percentage of the maximum flow (initial flow without thrombus).

Fig. 6. Setup for debris collection (A). The $100 \mu \mathrm{m}$ and $40 \mu \mathrm{m}$ filters allowed to collect debris $>40 \mu \mathrm{m}$. Pictures $B$ and $C$ show debris $>100 \mu \mathrm{m}$ and pictures $D$ and $E$ show debris $>40$ $\mu \mathrm{m}$.

Fig. 7. Debris count $>40 \mu m$ according to the device's speed. Debris on filters of $40 \mu \mathrm{m}$ and $100 \mu \mathrm{m}$ were counted under light microscopy. 
Figure 1

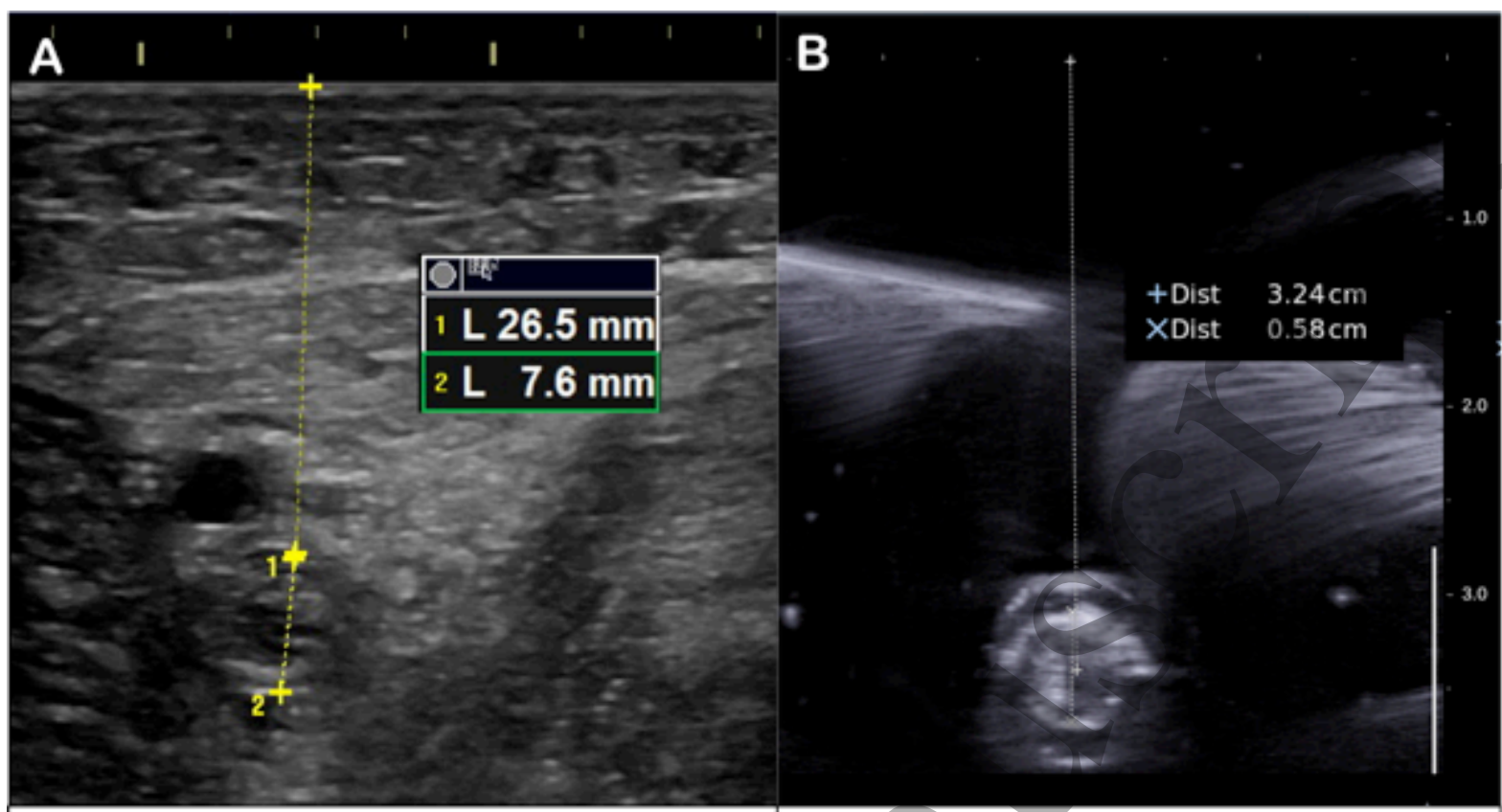

Thrombosed Femoral vein in a 63 years old patient

(Logic S8 ${ }^{\circ}$, GE Healthcare ${ }^{\circ}, 2-11 \mathrm{MHz}$ linear probe)
Occlusive thrombus in a silicon tube before thrombotripsy 
$1 \quad$ Figure 2

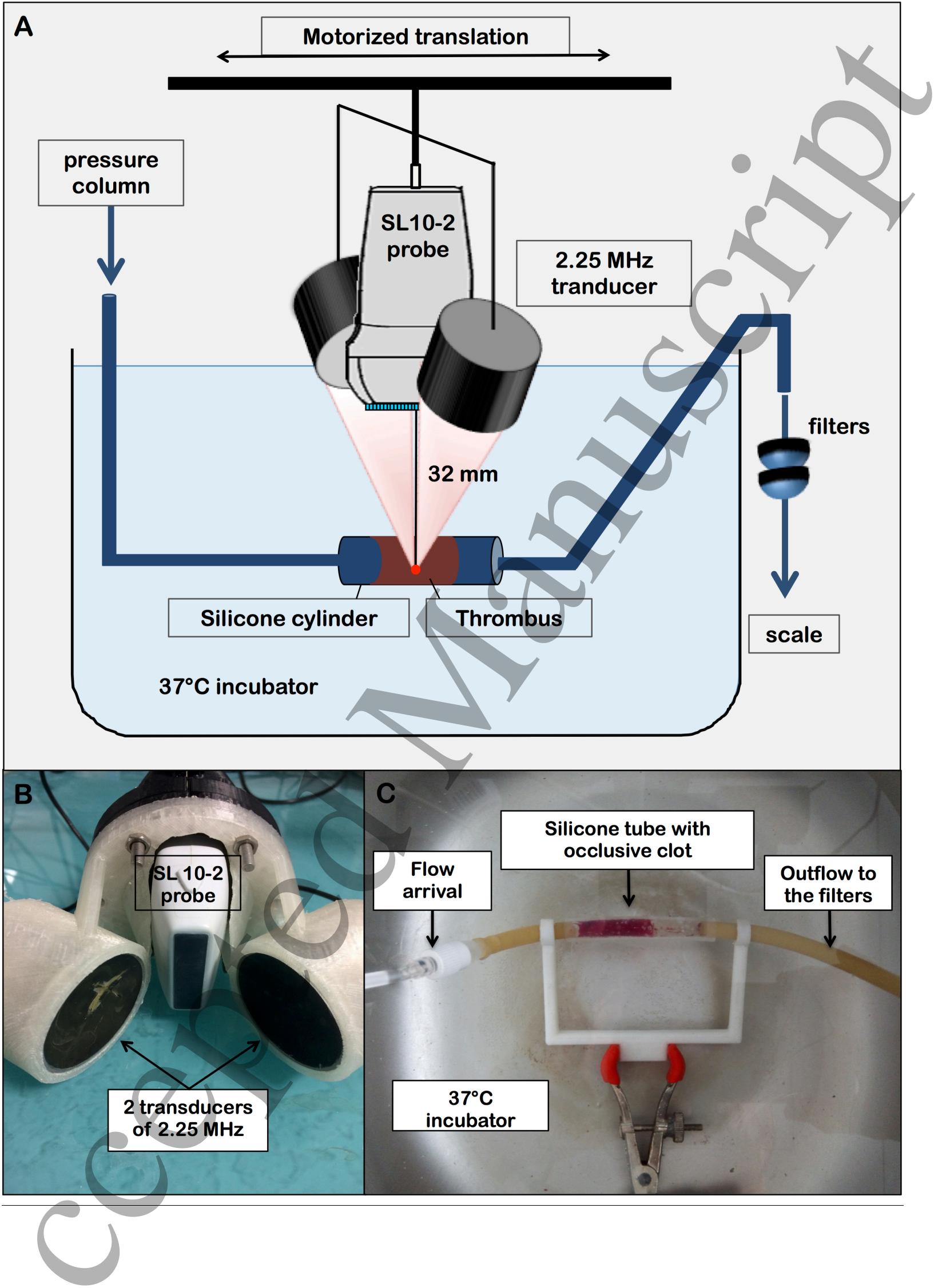


$1 \quad$ Figure 3

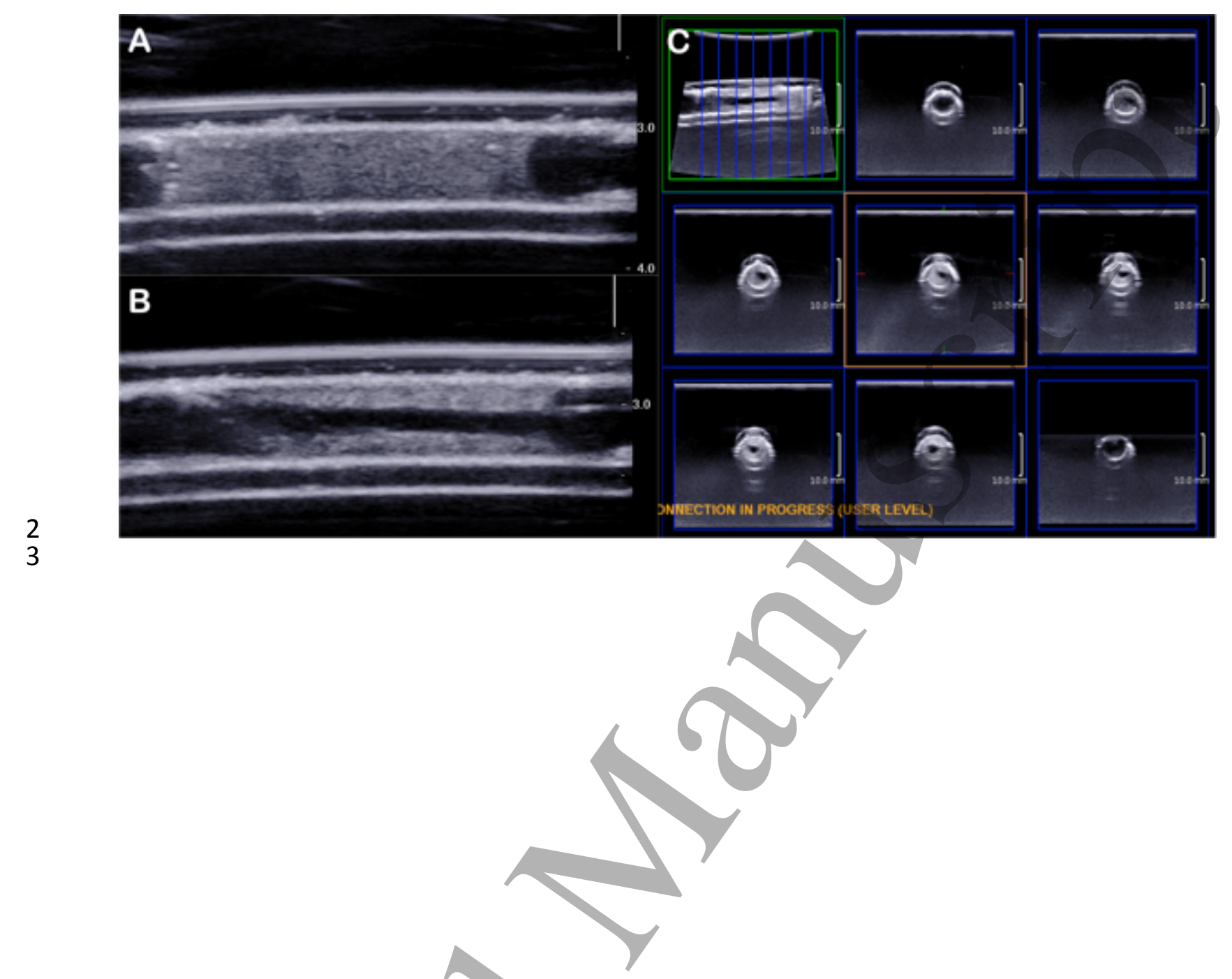




\section{$1 \quad$ Figure 4}
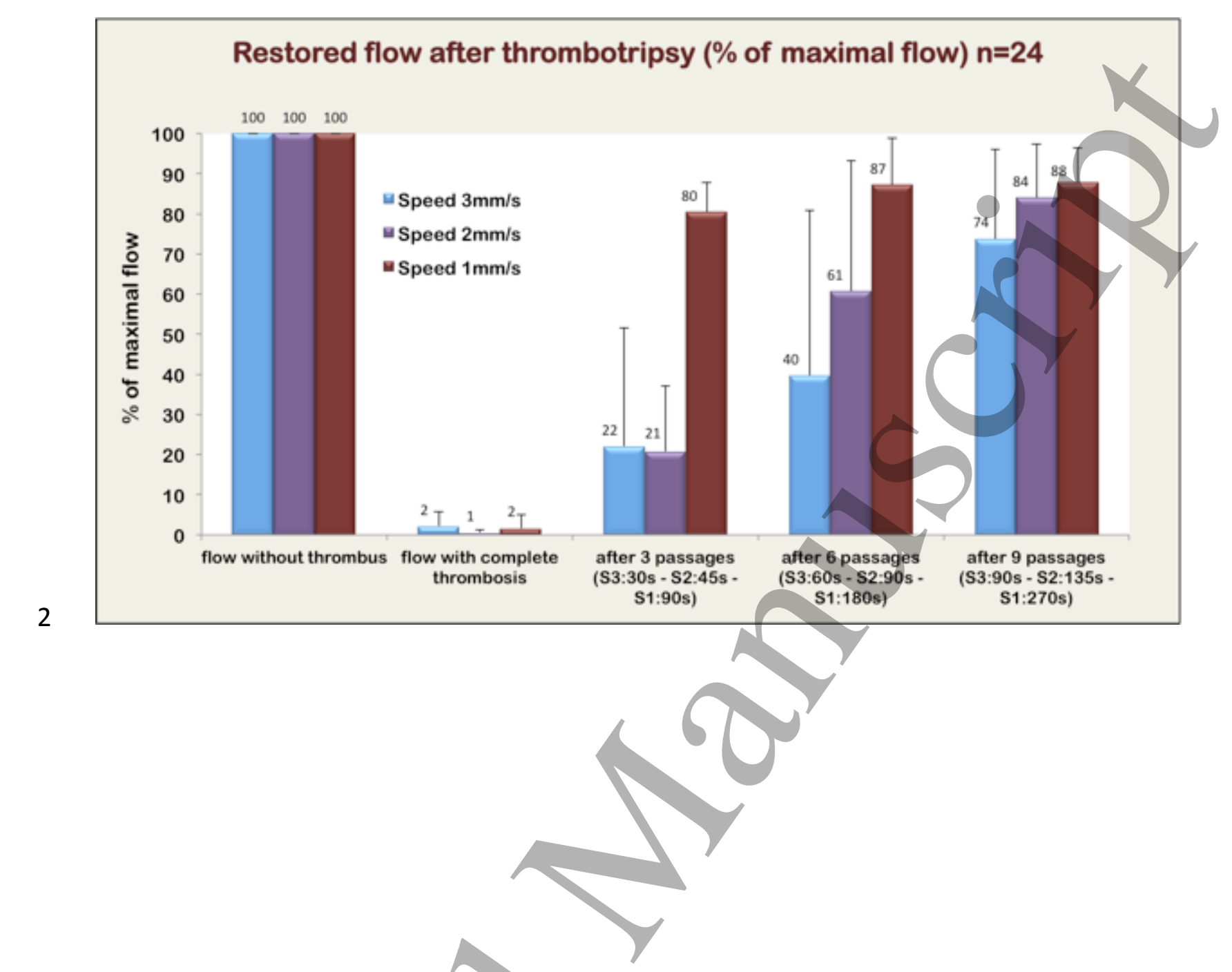

478


$1 \quad$ Figure 5

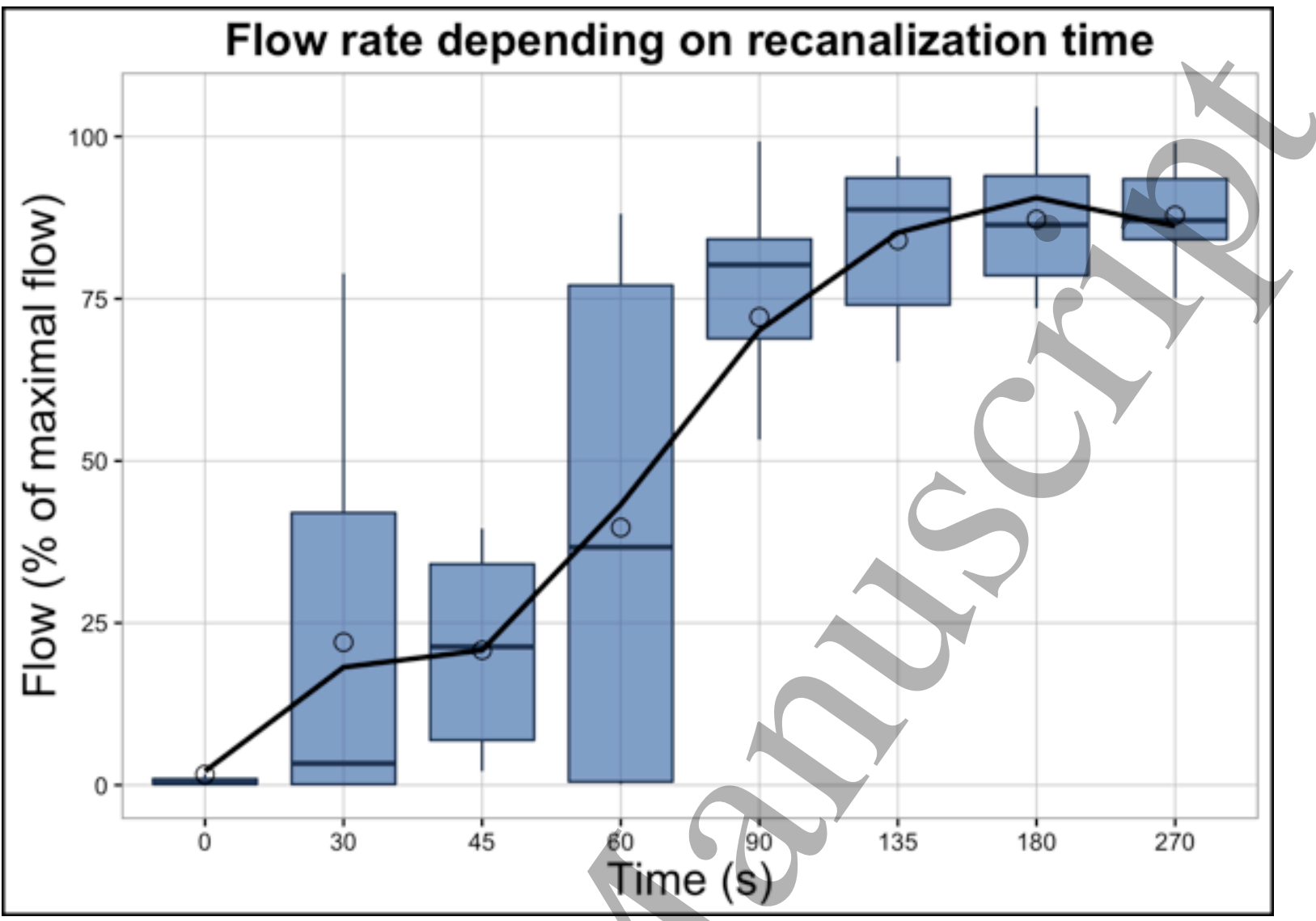


$1 \quad$ Figure 6

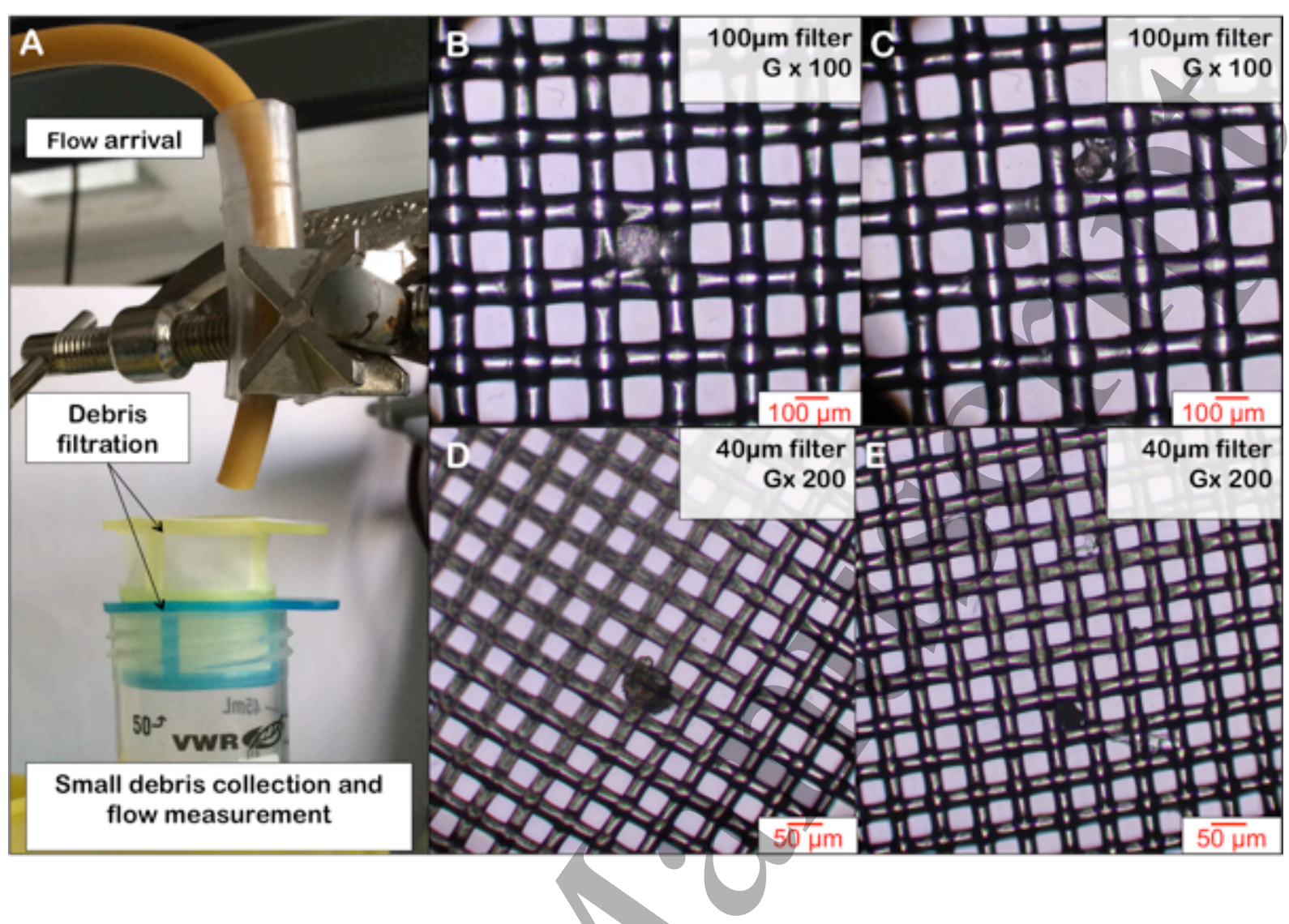


$1 \quad$ Figure 7

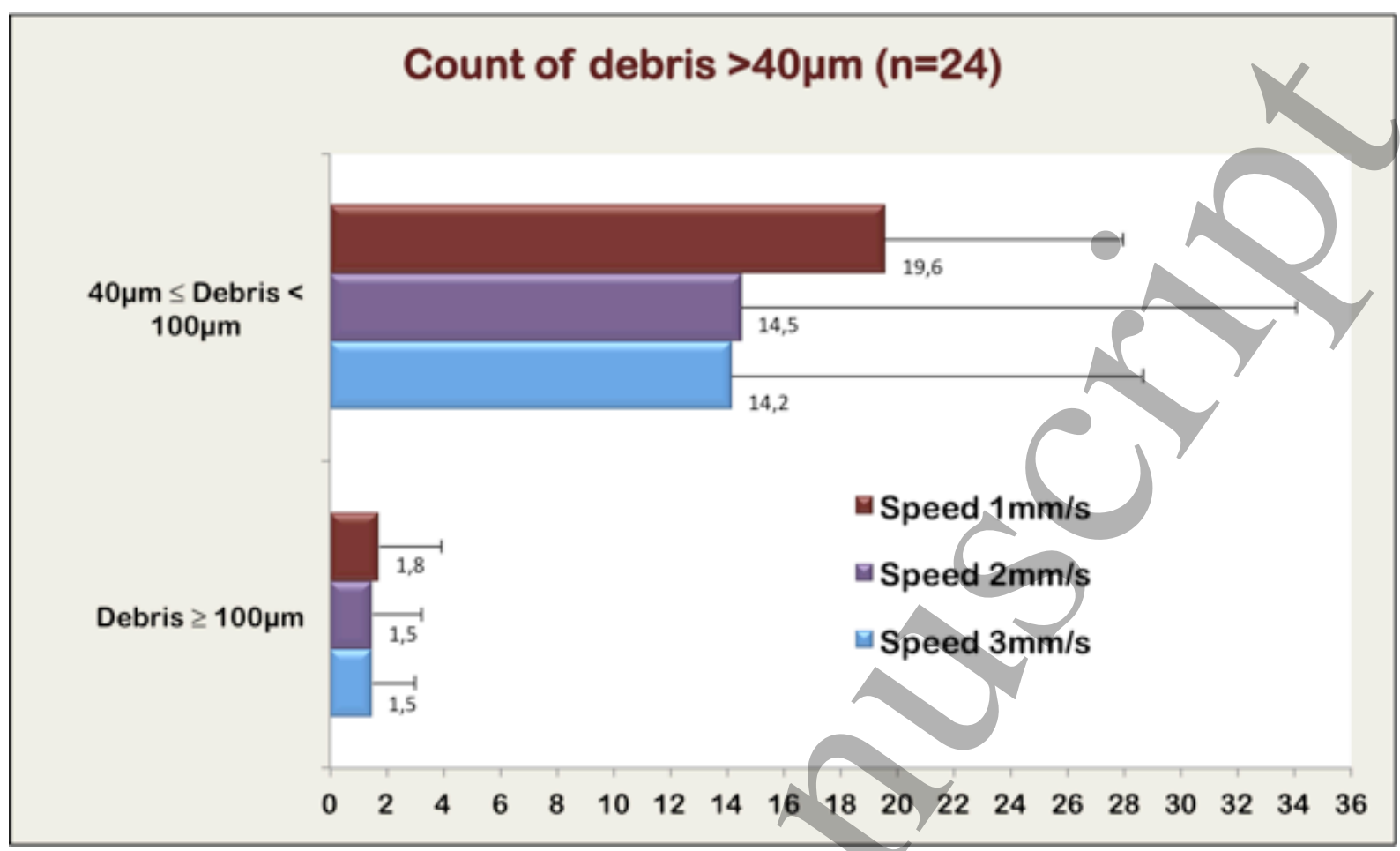

2
3 
$1 \quad$ Figure 8

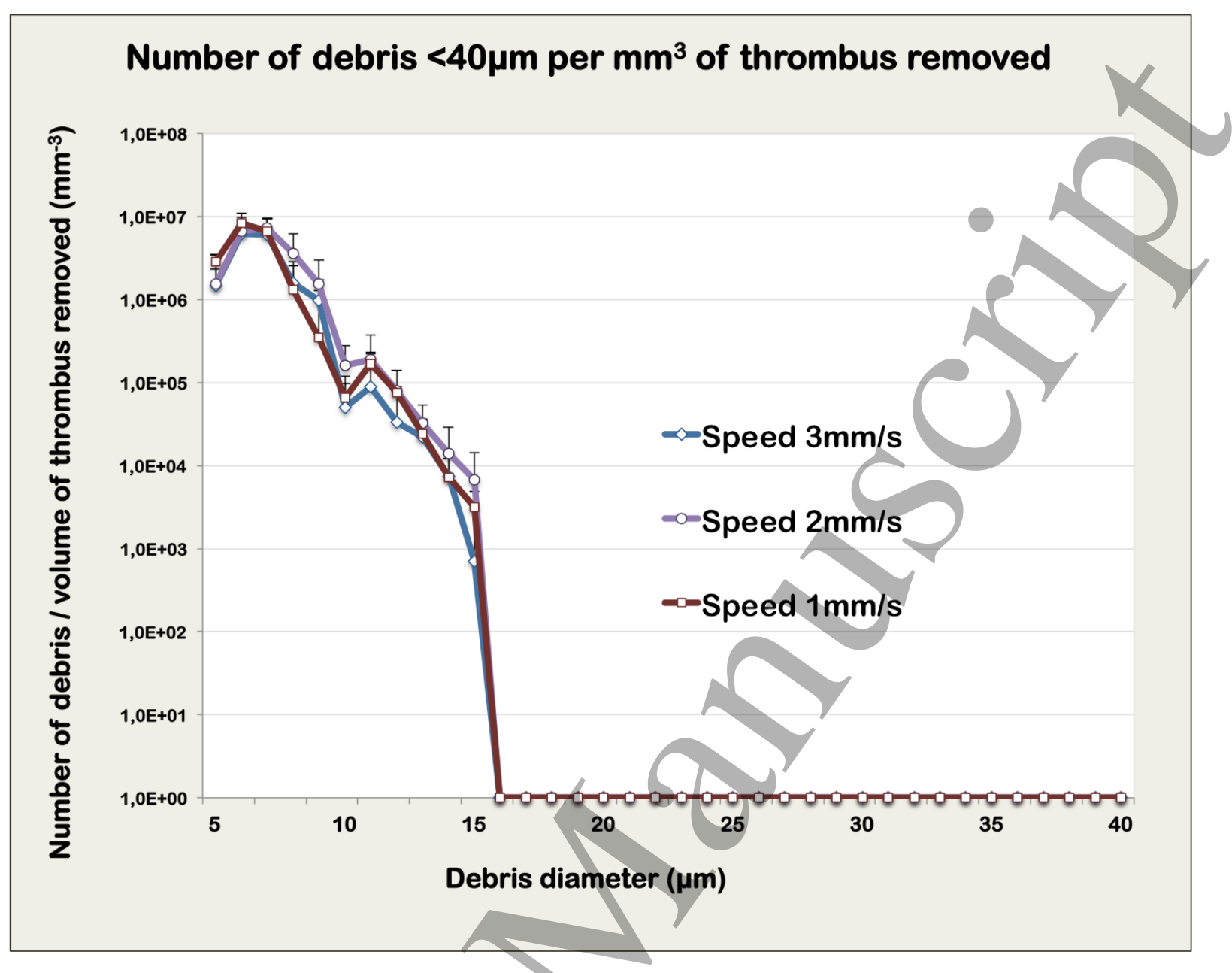

